\title{
TRAJETÓRIAS DE FEIRANTES IDOSOS: RELAÇÕES DE PROXIMIDADE. CORPO E TRABALHO
}

\author{
Samuel Pires Melo'
}

resumo

O presente artigo tem o objetivo de discutir as múltiplas concepções de trabalho, corpo e envelhecimento através das relações de proximidade firmadas na trajetória de feirantes idosos da feira de Delmiro Gouveia-AL. A pesquisa foi realizada sob o viés quali-quantitativo. Os dados foram obtidos através de pesquisa de campo, com as técnicas questionários e entrevistas semi-estruturadas. 0 estudo demonstrou ser necessário desprender do olhar ora físico ou simplesmente social para mostrar que as trajetórias de vida desses sujeitos estão firmadas pelas relações de proximidade, desde as ordens produtivo-econômicas às de natureza social e política, que permitem sua reprodução social.

palavras-chave

Envelhecimento. Corpo. Trabalho. Relações de Proximidade.

1 Graduado em Ciências Sociais pela Universidade Federal do Piauí (2005), mestre em Sociologia pela Universidade Federal de Sergipe (2009) e doutor em Sociologia pela Universidade Federal de Pernambuco (2012). Atualmente é professor da Universidade Federal do Piauí e trabalha nas seguintes temáticas: Antropologia da Saúde/Doença; Sociologia Rural; Ação Coletiva; Políticas Públicas e "Sociedade, Natureza e Desenvolvimento". E-mail: sampires@hotmail.com 
As discussões em torno das relações entre trabalho, corpo e envelhecimento têm sido resultantes, em maior frequência, de um significativo aumento proporcional de idosos na população, o que tem gerado diferentes rearranjos de modos de viver e trabalhar. Na verdade, as realidades em que esses processos se constroem revelam que as mínimas condições de permanência nem sempre são garantidas à população idosa, e que a depender dos grupos socioeconômicos, políticos e culturais que participam, os modos de viver e trabalhar destes sujeitos podem estar circunscritos em problemas de ordem material e simbólica. Nesse sentido, a necessidade de compreendermos melhor o processo de envelhecimento e suas conseqüências tem impulsionado a institucionalização e a consolidação dessa área de estudo.

Justapondo-se e/ou em contraponto a essas perspectivas, temos a realidade dos feirantes idosos da feira de Delmiro Gouveia, Alagoas. Eles correspondem a $15,7 \%$ do total de feirantes dessa praça de comércio ${ }^{2}$, com idades que variam de 60 a 90 anos. Vale ressaltar que quase a metade $(46,3 \%)$ desses sujeitos a trabalhar nessa feira tem entre 40 e 59 anos, representando um grande grupo em processo de envelhecimento. É importante dizer também que existe um grupo significativo de jovem-adultos $(38,1 \%)$ em interação com os idosos.

A justificativa em compreender a complexidade desses sujeitos feirantes está no fato de eles representarem grupos de trabalhadores inseridos de forma precária dentro da estrutura social, seja por sempre terem feito parte dessa atividade de feirante e/ou por terem se aposentado em outra e encontrado nessa uma forma de sobrevivência de seus grupos e, indiretamente, de uma parcela da população. Por isso, torna-se instigante estudar como esses sujeitos, exteriormente vistos como outsiders, interagem socialmente, principalmente a partir do papel social de feirante idoso.

As técnicas utilizadas para esta pesquisa, considerando-se os objetivos do estudo, foram os questionários e a entrevista semi-estruturada, com registro em formulário criado para tal finalidade, além da observação livre. Os questionários e as entrevistas semi-estruturadas foram realizados junto a indivíduos com idade igual e superior a 60 anos. Os sujeitos da pesquisa foram identificados no universo de 350 feirantes da feira do município de Delmiro Gouveia - Alagoas. Foram selecionados todos os feirantes idosos

2 Na denominação do termo, praça de comércio baseia-se em Garcia-Parpet (1984), para quem utiliza com a mesma denominação de feira-livre. 
encontrados e que se dispuseram a participar da pesquisa. Além disso, salientamos que os nomes dos pesquisados foram alterados para preservar sua identidade.

Para encadear nossa discussão utilizamo-nos das ferramentas teóricas de Marcel Mauss (1974) e Norbert Elias (1980), no que diz respeito detidamente à perspectiva do entendimento das relações de poder constituídas pelas experiências de feirantes idosos. Isto é, o envelhecimento, seus significados e a forma como o entendem constituem parte de uma problemática relacionada à estrutura dos grupos e do tipo específico de coerção a que os indivíduos estão expostos e se constituindo.

\section{Aspectos histórico-relacionais do envelhecimento}

Admite-se cada vez mais a complexidade do que caracteriza o processo de envelhecimento. Ele envolve muito mais que o corpo per si do indivíduo, é causado por fatores múltiplos que associam aspectos genéticos, ambientais, socioeconômicos e culturais. Salientam Minayo e Coimbra (2002) que "o ciclo biológico próprio do ser humano assemelha-se ao dos demais seres vivos todos nascem, crescem e morrem -; por outro lado, as várias etapas da vida são social e culturalmente construídas".

Apesar dos processos sociais ocorridos historicamente, Silva (2003, p. 110) salienta que "a condição do velho na atualidade não tem revelado grandes alterações dos tempos remotos". Para se ter ideia, na história do pensamento ocidental, como na Grécia Antiga, afirmam Braunstein e Pépin (1999), não se verificava uma unidade total no entendimento do que era ser mais velho. No século XVIII, observa-se por toda a Europa um processo de dissecação da imagem do idoso apesar de um aumento da população; devido ao processo de industrialização e seus desdobramentos, inclusive com uma melhor higiene, o domínio do velho na instituição familiar e na sociedade toma novas roupagens. Na verdade, acredita-se que o fim do prestígio consultivo dessa categoria social se deva à Revolução Industrial, que ocorreu no fim do referido século, e que pode ser considerada a causa fundamental de grandes transformações estruturais. Para Silva (2003, p. 110), "a urbanização e a industrialização acentuaram as desigualdades que, associadas aos preconceitos e estigmas, vêm demonstrando que as experiências acumuladas durante a vida não estão sendo aceitas pelos mais jovens".

O atual contexto de modos de viver e trabalhar, os chamados "novos paradigmas de produzir e viver", da sociedade moderna estão baseados, sobretudo, 
nos conceitos de velocidade, produtividade, eficácia, flexibilização, atualização, envolvimento, trabalho em equipe, etc. E os profissionais mais velhos, por sua vez, são tidos como lentos, improdutivos, ineficazes, rígidos, desatualizados, rebeldes e sem habilidades para trabalhar em equipe.

Mais do que uma "concepção de mundo", Beauvoir (1990) argumenta que as concepções de velhice variam conforme o interesse das classes sociais, manifestas pelos legisladores e moralistas, e que estão sempre relacionadas com a questão do poder, pois até o século XIX ela não encontrou referência aos velhos pobres, que eram pouco numerosos e possuíam vida mais curta. Além disso, Mascaro (1997) observa uma distinção em relação ao gênero, pois a velhice idealizada e prestigiada na mitologia e no folclore é representada, na maioria das vezes, pela imagem do homem idoso cheio de vigor, bondade e sabedoria, enquanto que a imagem da velhice feminina se associa com o lado negativo e sombrio da vida.

Nesse sentido, o século XX fragilizou ainda mais a imagem do idoso, sobretudo estereotipando uma percepção linear de fragilidade biopsíquica, além da decadência, resultante da perda de status econômico e social, quando o mundo passa a ser dominado por quem detém a força de trabalho, ou seja, os jovens. Ao enraizar essa concepção positiva do ser jovem, essa mesma sociedade passa a introjetar uma perspectiva do rejuvenescimento do idoso, através da busca pelo corpo jovem.

Como afirmou Mauss (1974), é por meio da "imitação prestigiosa" que os indivíduos de cada cultura constroem seus corpos e comportamentos. Para Mauss, o conjunto de hábitos, costumes, crenças e tradições que caracterizam uma cultura também se refere ao corpo. Assim, há uma construção cultural do corpo, com a valorização de certos atributos e comportamentos em detrimento de outros, fazendo com que haja um corpo típico para cada sociedade. Esse corpo, que pode variar de acordo com o contexto histórico e cultural, é adquirido pelos membros da sociedade por meio da "imitação prestigiosa". Os indivíduos imitam atos, comportamentos e corpos que obtiveram êxito e que têm prestígio em sua cultura.

A análise apresentada por Mauss (1974) é importante para compreendermos o papel social que o corpo tem na perspectiva das condições de trabalho, já que se tem este como maior preditor da qualidade de uma pessoa. Isso pode ser evidenciado nas experiências dos idosos quando relatam a velhice como perda corporal e mental de capacidade laborativa e a aposentadoria como fraqueza do sujeito. Por exemplo, Jordão Netto $(1997$, p. 65) afirma que 
Aposentadoria significa uma espécie de "atestado oficial" de envelhecimento do sujeito, um símbolo do ritual de passagem que vai estigmatizá-lo como um "inativo" e decretar, em última análise, sua velhice como agente produtivo e por extensão, sua velhice também como ator social.

Entretanto, essa concepção da aposentadoria não é geral e deve ser explorada, pois a depender das teias de conexão a que certos sujeitos estejam circunscritos, ela vem para garantir uma melhor qualidade de vida, como sendo uma renda a mais, já que ele não deixa de permanecer exercendo uma atividade produtiva.

O importante a observar é que o exercício de uma profissão possibilita ao sujeito se manter nos espaços de interação social e assim ter um sentido de existência e identidade social, conforme mostra Santos (1990). Pensando então nessa diversidade de formas de viver e trabalhar que tornam a experiência de idosos complexa, mas de fundamental importância de compreensão, é que propomos, nos tópicos seguintes, elencar aspectos do modo de viver e trabalhar de idosos feirantes do sertão alagoano.

\section{Trajetórias dos feirantes idosos}

Os modos de viver e trabalhar dos feirantes idosos pesquisados estão inseridos em trajetórias que trazem no seu cerne os valores de confiança, reputação, honra e responsabilidade, características estas que marcam a análise da produção e reprodução social. Com o objetivo de delinear melhor esses valores, faremos uma interpretação da feira de Delmiro Gouveia pelas experiências dos feirantes em figurações sociais.

As figurações que se sobressaem na compreensão desses valores são: grupos domésticos, sítios/povoados, pequenos municípios/bairros e feiras. Elas permitem conhecer melhor as relações de ordens produtivo/econômica e social/política de idosos feirantes. O conceito de figuração pode ser aplicado onde quer que se formem conexões e teias de interdependência humana, seja em grupos relativamente pequenos ou em agrupamentos maiores. Esse conceito é importante como instrumental para compreender um padrão mutável no jogo das relações, cuja interdependência entre os sujeitos sociais forma um entrelaçamento flexível e com tensões (ELIAS, 1980, p. 142). 
A (re)produção social dos feirantes idosos tem nos grupos domésticos um fator primordial. Na verdade, é por meio do grupo doméstico que as interrelações desses indivíduos são firmadas, impedindo um processo de individualização do idoso que pode conduzir a sentimentos de solidão e isolamento emocional. Vejamos como se constroem essas teias de relações.

Todos os feirantes idosos pesquisados mantiveram/mantêm laços parentais, sendo que atualmente $64,9 \%$ são casados ou moram juntos, $18,5 \%$ são viúvos e $16,7 \%$ solteiros ou separados. Dessas duas últimas categorias, todos estabelecem laços com parentes para ajudá-los na sua manutenção doméstica e na atividade na feira. Principalmente as filhas, realizando as atividades domésticas e, esporadicamente, na feira; e os filhos com os produtos a serem comercializados na praça de comércio. Esses dados são importantes para dizer que, independentemente do sexo ${ }^{3}$, os idosos precisam manter um laço maior de proximidade para manutenção das condições de vida.

Para o senhor Antonio ${ }^{4}$, o importante é não deixar de fazer o que gosta, e fazer o que gosta é "não deixar a vida de trabalhar e viver no passado", e mais, para que isso aconteça é necessário ter pessoas que possam "ajudar em alguma coisa que não se consegue fazer sozinho". "Ah, meu filho! Todo dia eu peço a Deus que meus meninos não mudem o juízo deles! Porque a gente só escuta falar do filho matando o pai, deixando morrerem à 'míngua', porque, no final das contas, o nosso corpo já está cansado, e não dá para viver como antes".

À medida que a pessoa envelhece, sua qualidade de vida se vê determinada, em grande parte, por sua capacidade para manter a autonomia e a independência. A maioria dos idosos teme a velhice pela possibilidade de tornarem-se dependentes pela doença ou por não poderem exercer suas atividades cotidianas. Tal evento fortalece a abordagem de manutenção de vida saudável, que significa comprimir morbidade, prevenindo-se as incapacidades (FREITAS et al., 2010, p. 410).

Existe um sentimento de continuar vivendo que se mistura às perdas caracterizadas de diversas formas: a perda de parentes e vizinhos, da força produtiva, da saúde e da beleza. Quando se pensa nos parentes e vizinhos, os feirantes levantam a questão da finitude da vida e da proximidade da morte

\footnotetext{
3 O número de mulheres viúvas/solteiras/separadas é maior (44,8\%) que o de homens (24,0\%).

4 Tem 72 anos. Viúvo, mora sozinho, mas conta com a ajuda da filha e netas nas atividades domésticas, e do genro para levar a produção deles do sítio para a feira.
} 
diante do desejo de permanência e apego às novas gerações familiares. $O$ idoso acarreta um sentimento de falta de expectativa de vida, relacionada à inexorabilidade da morte, à impossibilidade de se lutar contra ela e de se adequar às mudanças que passam as gerações. A senhora Maria José ${ }^{5}$ se remete a uma fragilidade física e social ao seu modo de viver e trabalhar. Segundo ela,

[...] a gente vai perdendo as forças, a energia. Na verdade, a gente vai perdendo é quase tudo. Quando chegam os 60, aí é fogo... [...] ainda mais quando a gente trabalha desde pequena e não para mais, pelo contrário, quando a gente tem família sempre tem que pegar mais no pesado, aí a gente acostuma mesmo, quando chega nos 60, a gente sofre um baque muito grande [...] ainda bem que o povo da gente sempre ajuda, porque senão, nem sei o que seria de mim.

Podemos observar que a família é, para os entrevistados, um suporte na proteção ao idoso, sendo o ambiente familiar o espaço para dispensar o cuidado. Essa perspectiva está relacionada, entre outras, à noção de que a família é a instituição mediadora principal entre o indivíduo e sua realidade circundante. A relação de cuidado que se estabelece entre a família e seu idoso ocorre com base no significado da família e da velhice. No caso do senhor Antônio e da senhora Maria José, existe uma trajetória de responsabilidade que os filhos têm para com seus pais, ela está fundamentada na perspectiva de uma reciprocidade esperada, que se manifesta na retribuição pelo cuidado recebido na infância e no amor filial.

Para o senhor João Santana ${ }^{6}$, além do valor da reciprocidade esperada, os filhos enxergam nele uma ordem econômica e social, já que o dinheiro de sua aposentadoria e ganho na feira é para ajudar toda sua família. "Eh meu filho, aqui eu sou uma peça muito importante! Não que esteja alegando, não! Mas tudo que fiz e faço nessa vida é para minha família [...] Às vezes, alguns deles ficam com raiva porque quero economizar, não libero dinheiro para tudo que querem, mas, na verdade, só estou pensando neles, nos momentos de necessidade maior. A mulher mesmo fica toda desconfiada, mas depois ela entende por que faço isso".

\footnotetext{
5 Tem 65 anos. Viúva, mora com as netas que a ajudam nas atividades domésticas, de produção no sítio e da comercialização na feira.

6 Tem 69 anos, casado, com oito filhos que moram próximo a ele, e também os ajudam no trabalho da feira. É importante dizer que alguns dos seus filhos executam outras atividades, só os auxilia no dia da praça de comércio.
} 
De forma entrelaçada, a aposentadoria, que representa a realidade de $70 \%{ }^{7}$ dos feirantes idosos, tem acentuada influência na construção de estratégias que servem para a reprodução econômica, mas mais do que isso, para a identificação do papel permanente do idoso na reprodução social do grupo doméstico. Na verdade, a aposentadoria do idoso feirante é um novo momento para reafirmação dele tanto no espaço doméstico quanto nas redes sociais dos espaços públicos, como é o caso da feira.

Quando nos remetemos à discussão de gênero para analisar o papel da aposentadoria e demais recursos financeiros dos idosos dentro do grupo doméstico, podemos dizer que o homem idoso ${ }^{8}$, que acumulou recursos financeiros e com benefício previdenciário, tem a função de amparar os filhos e netos, enquanto a mulher idosa, muitas vezes, cuida do marido, dos filhos e dos netos, pois todo recurso fica sob os cuidados dos homens da família.

Essa condição construída nos leva a pensar em uma diversidade de situações vividas pelos idosos, pois em determinadas posições sociais, inclusive no modo de trabalhar, os trabalhadores mais velhos são relegados à improdutividade e ao isolamento, deixando de ser alvo da procura do mercado. Por outro lado, podemos observar na realidade dos feirantes idosos, embora dentro de hierarquias de poder, que esses têm a possibilidade, com a aposentadoria, de reafirmação de suas participações nas decisões familiares/feira e no processo de produção. Embora se observem contrastes entre gerações, principalmente porque os feirantes idosos não possuem motivação para as mudanças ou inovações, o sentido de continuidade está presente entre muitos. Isso pode ser analisado na fala da senhora Francisca Maria9 ,

O filho do João Macedo tomou de conta da banca do pai e da tia [...] ele agora está comprando dos fornecedores de Petrolina, Feira de Santana e Itabaiana, o negócio dele é vender mesmo, ele tem muitas novidades [...] às vezes percebo que Fizin [filho] também fica com a vontade de melhorar nossa banca, mas aí, sabe, ele é muito parecido com a gente [...] prefere não arriscar, compra daqui de perto mesmo, às vezes traz do sítio do sogro, dele também, e aí vai dando para a gente ir passando.

\footnotetext{
7 Chama-se atenção para esses dados porque embora estes idosos estejam perfazendo o critério de idade cronológica para se aposentar, isso não é possível para todos; o que está relacionado principalmente à característica desse grupo social não pertencer a uma categoria profissional reconhecida como trabalho formal, e mais do que isso, os mesmos não puderem e/ou reconhecerem como profissão autônoma em que se deve pagar previdência. A outra parte que se aposentou exercia outra profissão, além de feirante, o que possibilitou o benefício.

8 Representa 45,5\% do total de feirantes idosos.

9 Tem 64 anos, viúva, com quatro filhos que moram próximo e um que reside com ela e é responsável pelo grupo doméstico. É importante dizer que alguns dos seus filhos executam outras atividades, só auxiliam no dia da praça de comércio quando necessário.
} 
É interessante salientar que, para muitos feirantes, o sentido de continuidade os permite - mesmo quando chega à velhice, onde diminuem o ritmo de atividades que exerciam satisfatoriamente - manterem o nível de equilíbrio. Isso é possível porque o que se consideram como mudanças nas condições de trabalho não os impede de se manterem nelas. Entretanto, apontam a velhice como veículo possibilitador de alterações no corpo que os impede de realizar coisas que gostavam de fazer ou faziam com facilidade e com destaque entre outros. Não apenas a velhice, mas também a ocorrência de doenças os impede o livre exercício dos corpos na execução de tais atividades. Comparam, ainda, a chegada da velhice com a proximidade do final dos sonhos.

Vale considerar, nesse sentido, que dentro do grupo doméstico homens e mulheres sempre trabalharam e envelhecem trabalhando. É importante dizer ainda que o grupo doméstico não se restringe a um espaço físico da casa, eles tecem outros territórios, como o da feira, por exemplo. Nela são encontradas pessoas mais velhas, tanto aquelas que nunca foram formalmente empregadas porque não tiveram oportunidades educacionais para tanto, ou não reconheceram como importante, quanto aquelas que já foram jubiladas do trabalho formal, e agora estão principalmente como feirantes. Isso é possível porque existem mecanismos de interações sociais construídos sob valores de confiança, reputação, honra e responsabilidade.

É importante dizer também que os valores supracitados ultrapassam as interações pais e filhos, encontrando nos demais parentes, vizinhos e amigos meios considerados preponderantes no firmamento da continuidade dos modos de viver e trabalhar de idosos feirantes. Embora, aparentemente, pensemos ser a velhice um momento de isolamento, para esses sujeitos, acontece o firmamento dos laços sociais. Para se ter uma ideia, como veremos nas figurações dos sítios/povoados e bairros/pequenos municípios, essas redes de relações (re)construídas, a princípio desde a família, vão sendo ampliadas à medida que se incluem amigos, colegas de trabalho, da igreja, de festas e outras atividades de viver e trabalhar, além de relações sociais baseadas em atividades outras, como de cuidados de saúde.

\subsection{Sítios/povoados}

Embora em cada momento se precise identificar ou nos situar, nós usamos escalas geográficas como sítio/povoado e bairro/cidade para dizermos a nós mesmos e a outras pessoas quem somos, de onde somos, para onde 
fomos, de onde viemos e onde vivemos. A referência que aqui fazemos dos sítios e povoados pode ser vista de forma convergente quando se tratam de serem definidores de espaços de produção e reprodução dos idosos agricultores familiares e feirantes.

Remetemo-nos, assim, ao sítio como lugar onde se mora e trabalha como camponês. O povoado como um lugar ainda plenamente rural, mas já não selvagem e é o lugar da vida para onde converge o trabalho camponês é o lugar que torna estável a cultura rural e, sobretudo, faculta que se torne comunitária a vida familiar dos sítios (BRANDÃO, 1995).

Em se tratando da proporção de feirantes idosos que moram em sítios e povoados, podemos dizer que menos da metade $(32,7 \%)$ do total deles residem nesses espaços. É importante salientar que encontramos nas falas dos pesquisados, tanto dos que moram em sítios/povoados quanto de moradores dos pequenos municípios, o desejo de permanecer, ir ou voltar a morar em territórios rurais. No entanto, esses não encontram meios que possibilitem sua manutenção nesses espaços, devido principalmente à falta de bens e serviços oferecidos.

O desejo por ficar ou ir aos sítios/povoados está relacionado aos mecanismos de valores que possibilitam a manutenção dos modos de viver $e$ trabalhar dos feirantes idosos, típico das sociedades camponesas. Para Mendras (1978), essas sociedades estão organizadas em relações de interconhecimento, que são atividades sociais particulares de cada comunidade; resultam de práticas e representações particulares a respeito de espaço, tempo, família, terra, trabalho, entre outras. Isso denota que os camponeses estabelecem relações personalizadas, próximas, de alto grau de conhecimento entre as pessoas da comunidade. "Interconhecimento significa conhecimento total e prolongado da pessoa do outro, das posições sociais atuais e passadas, das particularidades de sua personalidade" (MENDRAS, 1978, p. 88).

Sabourin (2009) argumenta que a reprodução do modo de vida desses agentes se interconecta às relações de reciprocidade, eles se opõem concretamente em adotar a lógica da individualidade, onde cada um com seu modo de viver e trabalhar busca maximizar sua produção social e assim manter sua reprodução social. Buscando preservar a autonomia de definir sua vida, o camponês de hoje busca na solidariedade local e na potencialização de relações favoráveis com as instituições estatais constituir uma forma de sobrevivência.

Portanto, mesmo diante dessas disparidades, o que garante a reprodução social desses idosos é a formas como se organizam desde o grupo doméstico às demais interações sociais, principalmente pelo interconhecimento 
local. Os componentes intervenientes nessa rede social se encontram perpassados por amigos e vizinhos dos feirantes idosos, que podem ser descritos através do tempo de residência no local e os recursos utilizados para se manter contato com os amigos e estabelecimento de reciprocidade com amizades sólidas.

As relações de proximidade provenientes do tempo de moradia e conhecimento entre os residentes dos povoados e sítios mostraram ser estes os fatores que interferem na amizade do feirante idoso com os vizinhos, sendo que este vínculo tem uma característica tanto mais tênue quanto menor for o tempo de interconhecimento local, como se observa na fala de Francisca Maria ${ }^{10}$ :

Quando era jovem ficava, às vezes, chateada pela forma como os outros davam conta da vida da gente, não podíamos nem ir ali que o pessoal já contava para minha mãe, ficava com tanta raiva. Mas hoje eu entendo que isso é para o bem da gente, para não fazermos besteira, coisa para não ficar mal vista. Além do mais, tem dessas mesmas pessoas que falavam da gente, é quem a gente pode contar nos momentos de maior necessidade [...] mas nem todas elas, claro.

Para os feirantes idosos, a proximidade com os vizinhos é importante e benéfica, à medida que lhes permitem perceber que podem contar com os vizinhos para continuar os seus modos de viver e trabalhar. De fato, eles acionam essa rede diariamente com a contratação de serviços que variam desde a limpeza do espaço doméstico às atividades relacionadas à produção; existe também o auxilio no transporte e venda de seus produtos na feira, além de ajudarem de outras formas como na troca de informações ou palavras afetuosas. No entendimento dos feirantes idosos, o interconhecimento local é construído no dia-a-dia do ambiente familiar, sendo os vizinhos e amigos considerados seus irmãos, filhos ou o próprio companheiro(a). Na fala de Dona Justina ${ }^{11}$, podemos observar quais teias estão mais presentes no firmamento dos seus modos de viver e trabalhar:

Ah, aqui a gente conhece todo mundo, todo mundo é parente, e se não é parente direto, mas é parente de parente da gente, aí já viu, né? [...] com certeza tem uns que a gente é mais próximo, né? Aí com eles a gente conversa mais, logo porque com eles a gente também tem mais negócio [...] de comprar

\footnotetext{
10 Tem 61 anos, viúva, com seis filhos que moram próximo a ela. É importante dizer que alguns dos seus filhos executam outras atividades, só auxilia no dia da praça de comércio quando necessário.

11 Tem 66 anos, casada, com nove filhos que moram próximo e dois que residem com ela. Mas, segundo eles, essa situação é temporária, até casar novamente. O esposo e esses filhos que moram com ela são responsáveis pelo grupo doméstico. É importante dizer que alguns dos seus filhos executam outras atividades, só quem auxilia no dia da praça de comércio são os que moram na residência dela.
}

(1)


as coisas juntos, contratar um carro para levar nossas coisas para vender na feira e também para confiar que nossos filhos e netos possam andar com os filhos e netos deles.

Vale notar que a amizade entre eles apresenta diferentes escalas de intensidade e, às vezes, quando o vínculo se caracteriza apenas por conversas informais e superficiais, também são, de certa forma, incluídos na rede de relações. Isso porque independente da escala de interação, a rede social representada nesses territórios desempenha um papel ativo importante no tocante a situações de doença para a procura do serviço de saúde, como lembra o senhor Inácio:

Repare, de onde a gente menos espera podemos encontrar uma alma boa [... ] Assim, na verdade, todo mundo aqui conhece uns aos outros [...] aí um dia desses, meu filho desmaiou e nós não sabíamos mais o que fazer. Pois aí você acredita que dona Lucilene [vizinha] foi perguntar se Chiquinho [outro vizinho mais distante], que nem nos conhecíamos direito, podia levar esse meu filho para o posto de saúde, ele nem titubeou, levou logo [...] é, depois eu descobri que a gente tinha parente em comum, porque ele é esposo da prima do cunhado do meu genro [...] é interessante isso, porque eu estava conversando com minha mulher que no final das contas todo mundo se conhece [risos].

Nesse sentido, essas teias de interação destacam-se por características importantes, como confiança, lealdade, empenho, tolerância, respeito, consideração, afeto e apoio. No entanto, os laços podem se tornar frágeis por quebra de valores partilhados entre eles, perde-se a confiança na pessoa em questão, resultando em uma condição negativa para a manutenção e continuidade do relacionamento, que pode ocasionar até mesmo a quebra do vínculo e dificuldade para iniciar novas amizades, a depender dos espaços que se inserem, como veremos na figuração dos pequenos municípios.

\subsection{Bairros/pequenos municípios}

Como falamos dos sítios/povoados, observamos que mais da metade dos feirantes idosos moram na cidade de Delmiro Gouveia-AL. O município objeto desse estudo é relevante pela característica de apresentar uma área urbana com uma porcentagem maior de população urbana em relação à própria microrregião. Embora não possua um cenário estritamente agrícola, a microrregião apresenta uma economia baseada em produtos agrícolas, principalmente comercializados nas feiras livres do alto Sertão Alagoano. 
Além disso, notam-se mecanismos de interação social presentes no meio rural, como os costumes, uma infraestrutura simples, administração familiar, festas religiosas e certa tradição que vem dos primeiros moradores da região.

Adotamos a definição de pequeno município sugerida por Wanderley (2001). Isto porque podemos compreender Delmiro Gouveia como majoritariamente urbana, com fortes traços das ruralidades, ou se enquadrando numa situação intermediária. Apesar de o município apresentar uma dinâmica que evidencia a presença de elementos do mundo rural, poderemos compreender, através das interações construídas por sujeitos sociais, no caso feirantes idosos, sua dinâmica urbana e rural que se configura nesse local.

O que caracteriza, na verdade, a urbanização deficiente (WANDERLEY, 2001) em Delmiro Gouveia é justamente o fato de que, por um lado, existe um hospital, escolas de ensino médio, de cursos técnicos e profissionalizantes e uma unidade de ensino superior, mas, por outro lado, estes apresentam condições de acesso aos serviços especializados escassas, realidade de boa parte das pequenas cidades. Esses elementos contribuem, de alguma forma, para a formação de uma mentalidade urbana, ao menos para aqueles que têm acesso aos recursos.

[...] O que posso lhe dizer é o seguinte: não troco o meu lugar por lugar nenhum! Eu sei que aqui para se conseguir alguma coisa é muito difícil, e ainda mais em se tratando de saúde, aí o negócio pega. Já tive de ir para casa do meu filho, em Maceió, porque estava com um problema muito sério, e aqui não tinha recursos médicos para tratar desse negócio, mas logo que pude voltei [...] Lá é muito ruim para a gente, igual a gente, viver! Veja, até para pegar um ônibus é um sacrifício tremendo, e a gente não tem condições de pagar o táxi, aí é assim [...] só saio daqui, moço, se perder meu sentido. Aqui eu tenho o mais importante, a tranquilidade de poder conviver com os meus (ANTONIA FRANCISCA ${ }^{12}$, 72 anos).

A entrevista com Antonia Francisca demonstra que a "cidade grande" está se transformando num ambiente hostil e não acolhedor a um idoso que tem algum grau de limitação; enquanto na "cidade pequena" as coisas são mais próximas, o idoso transita com facilidade. Além disso, na capital os familiares dos idosos são comprometidos com o trabalho. No interior sempre tem alguém mais perto para cuidar do idoso.

12 Casada, com três filhos que moram próximo e dois que residem em Maceió, segundo ela, embora tenha saudades dos filhos, considera que onde vivem é considerado o ponto de apoio deles. $\bigcirc$ esposo e os que moram perto dela ajudam na compra de produtos que serão comercializados na feira. 
Esse processo de interação possibilita que o rural esteja presente no consumo realizado pela sociedade urbana de bens simbólicos e materiais e de práticas culturais que são próprias do meio rural. Carneiro (1998) salienta que os elementos rurais e urbanos presentes no município estão intimamente ligados aos hábitos e costumes rurais que se configuram nas festividades, em eventos esportivos e também surgem nos costumes e hábitos diários da população urbana, formando assim um modo de vida característico do local.

O que se observa, por um lado, é a presença e a permanência de ruralidades em pequenos municípios como Delmiro Gouveia, preservando ainda um pouco da tradição e heranças históricas diante da racionalidade imposta pelas relações capitalistas. Por outro, é a cultura da sociedade moderna se transformando a partir desses processos de interação marcada por um forte laço da tradição. Conforme Candiotto e Corrêa (2008, p. 17),

[... assim como o espaço urbano e rural estão imbricados, o mesmo acontece com as ruralidades e urbanidades. Além da existência de atores, objetos técnicos e ações de caráter urbano no meio rural, conduzindo a urbanidades no espaço e na sociedade rural, existem ações e objetos técnicos característicos do rural (com origem rural ou industrialurbana) que acabam se inserindo no urbano (estilo country, músicas, festas, hortas), levando a ruralidades no espaço e na sociedade urbana.

Essa dimensão trata-se das relações sociais instituídas pelas várias formas de ocupação do espaço urbano. Diz respeito também à maneira como os sujeitos constroem suas teias de relações, como, por exemplo, o espaço onde moram. Nele, as práticas cotidianas são acionadas pelas manifestações culturais que são responsáveis pela construção de uma identidade local, mesmo que parte dessa população não tenha nascido nesse lugar.

É engraçado porque estou mais velho, mas aumenta mesmo a quantidade de coisas que temos que fazer e participar [...] é assim: vou ao banco tirar o aposento da mulher e o meu, lá revejo meus amigos, compadres e comadres; marco nossas consultas, lá também é cheio de conhecido, só fico triste por saber que alguns deles tenham partido dessa para melhor [tenham morrido]; vou à farmácia, compro os mantimentos para ela fazer as coisas que nós vendemos na feira, vamos todo santo domingo à missa, e não faltamos nos festejos. Aí meu filho, no final das contas a gente trabalha demais [...] mas se não fizesse essas atividades não sei o que seria de mim (LUIZ ANTONIO ${ }^{13}, 64$ anos).

13 Casado, e seus quatro filhos moram na cidade vizinha, Paulo Afonso-BA. 
As tarefas desempenhadas pelos idosos, apesar da significação do esforço físico, ganham contornos importantes para sua manutenção social. Essa significação está associada às teias de interações que conseguem manter ao longo de trajetória de vida ou novas que são construídas; nessa etapa de vida em que idosos se encontram, a inclusão da religiosidade nessas teias tomaria papel fundamental, tornando-se fonte de significado para a vida desses idosos, influenciando no bem-estar subjetivo deles (MALDAUN et al., 2008, p. 71). Entretanto, vale salientar que a religiosidade perpassa outras teias de significação, e que não necessariamente ela seja a mais importante, como mostra a feirante idosa Antonieta ${ }^{14}$.

Quando morávamos no povoado, íamos mais às celebrações da comunidade, mas aqui a gente vai mais é para os festejos assistir a missa, logo porque a feira é no sábado, aí temos que organizar depois as coisas [...] pois é, no domingo vêm os filhos, netos, noras, genros, aí já viu, temos muita coisa a fazer e conversar [...] no dia que eles não vêm, a minha vizinha, que é de dentro da igreja, me convida e nós vamos para missa, que é aqui no bairro mesmo.

A vizinhança, para Antonieta, tem um papel preponderante, principalmente para suprir as necessidades de interação deixadas pela família. $\mathrm{Na}$ constituição do espaço urbano, o bairro pode ser interpretado como uma espécie de microespaço que se integra à cidade, configurando-se enquanto lugar onde diferentes experiências da vida social acontecem, e que integram as pessoas, sem necessariamente estar vinculada a laços de sangue. As experiências compartilhadas pelas pessoas que convivem nesse espaço se constituem, por sua vez, em elementos fundamentais para a construção e manutenção dos laços sociais desse lugar. A exemplo disso, podemos analisar a fala da feirante idosa Franciane ${ }^{15}$ :

Eu dou graças a Deus ter duas vizinhas que são como irmãs para mim, principalmente depois que essa mulher [nora] veio morar aqui. Você me acredita que ela não deixa eu fazer mais nada, quer me privar até de ir para feira. E o bobo do meu filho faz tudo que ela quer, acredita? Mas graças a essas minhas vizinhas eu estou conseguindo impor a minha vontade, dou até, muitas vezes, o exemplo delas, que são iguais a mim e que fazem as mesmas coisas que eu, então por que não posso trabalhar? [...] é cada coisa!

\footnotetext{
14 Tem 60 anos, casada, com seis filhos que moram na cidade de Água Branca-AL. O esposo é responsável pelo grupo doméstico. É importante dizer que seus filhos executam outras atividades, só auxilia no dia da praça de comércio quando necessário.

15 Tem 69 anos, viúva, com quatro filhos que moram em outra cidade, e um residindo com ela. É importante dizer que o filho executa outras atividades, só auxilia no dia da praça de comércio quando a esposa não vai ajudar a feirante idosa Franciane.
} 
O discurso apresentado pela feirante idosa Franciane, sobre a maneira que a nora quer tratá-la, faz parte da construção social maior sobre o papel dos idosos na sociedade, inclusive na família, de incapazes. Para Bosi,

A moral oficial prega o respeito ao velho, mas quer convencê-lo a ceder seu
lugar aos jovens, afastá-lo delicada, mas firmemente dos postos de direção.
Que ele nos poupe de seus conselhos e se resigne a um papel passivo. Veja-se
no interior das famílias a cumplicidade dos adultos em manejar os velhos, em
imobilizá-los com cuidados "para o seu próprio bem". Em privá-los da liberdade
de escolha, em torná-los cada vez mais dependentes [...] (BOSI, 2010, p. 78).

Em síntese, os feirantes idosos que moram em sítios/povoados interagem frequentemente com os pequenos municípios. No entanto, feirantes idosos dos pequenos municípios não têm a mesma frequência nos espaços dos sítios/povoados. Por outro lado, com fluxos diferenciados, existe uma permanência de interação da cultura urbana no rural, e desta no urbano.

\subsection{Feira: seus ares de rupturas e continuidades \\ das relações sociais}

A feira de Delmiro Gouveia é resultante do processo de povoamento da região do Alto Sertão Alagoano. Sua forma e localização atual se deram pelo processo de modernização típica da região, estruturada pari passu com o mercado municipal. Historicamente, foi espaço de manutenção do poder dominante das elites, mas também de sobrevivência dos camponeses e trabalhadores urbanos desempregados da indústria têxtil ${ }^{16}$.

Atualmente, a feira de Delmiro Gouveia se estrutura como espaço de reprodução do capital, mas também de reprodução social de grupos marginalizados. Na verdade, na feira interagem pessoas de diversos espaços, grupos sociais que convivem socialmente; isso tem contribuído ora positiva ora negativamente para que as interações sociais de reciprocidade (as sucessivas socializações secundárias) possam estabelecer a mútua identificação de hábitos de vida entre elas - de maneira a que gerem tipificações e institucionalizações necessárias para o estabelecimento de um padrão comum de comportamento social - e, portanto, desenvolver rotinas sociais comuns entre eles na vida cotidiana.

16 Para uma compreensão mais aprofundada, ver o capítulo "o processo de territorialização do Alto Sertão de Alagoas e suas conexões com as histórias das feiras", da tese de doutoramento de Melo (2012). 
Em muitos dos casos estudados, foram as relações sociais de afinidades com vizinhos, amigos ou parentes que proporcionaram novas identificações sociais. Em outras circunstâncias, o processo de localização, comercialização e o forte individualismo reinante não proporcionaram contextos sociais nos quais as interações sociais de reciprocidade pudessem estabelecer mútuas identificações de hábitos, e, se aconteceram, eles não foram, para essas pessoas e famílias, considerados fundamentais. Sobre isso, salienta Antonieta:

\begin{abstract}
Minha relação com os outros feirantes é normal, a gente se fala quando precisa! É claro que tenho umas amigas aqui, né? Mas elas vendem é ali fora [...] essas daqui, que fica do lado de minha banca parece que quer só aparecer. Mas isso é porque a mãe delas deixou de tomar de conta da banca dela, entregou para as filhas, aí elas pensam porque são jovens, são melhores do que a gente, só que o negócio da feira a gente aprende é com os mais velhos. Não é que esteja querendo ser melhor, mas na minha banca não tem tempo ruim, enquanto na delas, só vivem reclamando [...] às vezes eu mando é gente que vem aqui comprar na banca delas, aí elas ficam me querendo bem.
\end{abstract}

Apesar das possibilidades de rupturas, ocasionadas principalmente pela perspectiva de individualidade, a feirante idosa Antonieta procura reatualizar suas relações utilizando-se dos seus valores de proximidade. Em outras palavras, o evento da feira pode ser considerado uma extensão dessas relações de proximidade que acontecem entre vizinhos, porém ampliada e certamente modificada. Nesse sentido, compreendemos que as interações estabelecidas no cotidiano (grupos domésticos e vizinhança) podem ser um sustentáculo para conexões ampliadas (feiras). Além disso, as interrelações pessoais facilmente se convertem em estruturas de apoio ou recursos sociais para agentes vinculados, ampliando suas capacidades de ação.

\begin{abstract}
É muito bom quando a gente tem um papel aqui na terra, né? Pois é, eu aprendi a importância que a natureza tem para nós, e como ela tem o poder de curar, aí o que eu faço é passar para as pessoas [...] mais do que vender aqui na feira, eu venho trazer a sabedoria que Deus me deu para curar todas as pessoas que vêm procurar-me, por isso que saio da minha casa, de perto do meu povo, para também oferecer o que Deus me deu para mais gente (FRANCISCO DOS ANJOS ${ }^{17}, 72$ anos)
\end{abstract}

A maneira como vai se constituindo a sociabilidade entre feirantes idosos, demais feirantes e consumidores mostra que a interação também

17 Viúvo, tem cinco filhos que moram próximo a ele e que ajudam nos "afazeres" domésticos. Vale dizer que dois deles também vendem na feira, só que verduras, frutas e roupas. 
requer proximidade pelos valores de confiança, reputação, honra e responsabilidade entre os participantes. Isso porque as feiras são vistas como um meio - de estratégias visando reprodução socioeconômica dos seus participantes e também um fim - a prática social fortalecida. A feira é salutar para a manutenção de todos os agentes envolvidos, tanto para os grupos que abastecem quanto para os que são abastecidos de produtos e aprendizados.

$\mathrm{O}$ fato de as feiras serem resultantes de outras figurações sociais, com níveis de diferenciações, não impede que elas sejam uma figuração ampliada. Na verdade, os seus fins são, de certa forma, alinhavados sob as perspectivas das figurações: grupo doméstico, sítios/povoados e pequenos municípios. Nesse último caso, as figurações feiras acionam inúmeras conexões com os pequenos municípios, que vão desde os poderes públicos municipais a serviços terceirizados, mercados, consumidores e feirantes variados. Por isso mesmo, elas têm de se atualizar diante das demandas dos mercados, das novidades e das diferentes medidas impostas ao setor, inclusive pela ideologia do "velho que atrapalha", como demonstra João Francisco ${ }^{18}$,

É duro ter de ver o próprio filho deixando seu filho falar mal do avô, ainda nem morri, e o menino já quer tomar minha banca, você acredita? [...] esse meu neto me ajuda passando troco, vendendo às vezes. Ele é bom, mas dizer que está na hora de eu abandonar o barco, ficar descansando em casa, é muito ruim, não sabe que isso aqui é o que me mantém vivo! Mas não fiquei calado, não. Disse que se quisesse ficar ajudando-me, seria de bom grado, mas querer tomar meu espaço, não aceitava. Ou ele comprava um para ele, aí chamava outro menino para ajudar, porque a família é grande, ou ficaria comigo até quando Deus quiser.

Os conflitos a que estão sujeitos os feirantes idosos são muitos. Os valores de confiança, reputação, honra e responsabilidade precisam ser significados continuamente para não perderem o poder constituído. No caso da feira, isso é possível porque mesmo não tendo o apoio de alguns para manutenção dos valores, existe um grande número de pessoas que partilham e procuram significar a importância desses sujeitos para reprodução dos seus grupos sociais.

\footnotetext{
18 Tem 82 anos, casado, com seis filhos que moram próximos, sendo que atualmente reside com filho mais velho. É importante dizer que seus filhos executam outras atividades, e este que reside tem uma banca também na feira e só o auxilia quando necessário.
} 
mais diversas figurações sociais, pudemos compreender os mecanismos que são (re)criados para reprodução social desses indivíduos. Analisar aspectos das ordens do produtivo-econômico às de natureza social e política possibilitou observar que as formas de viver e de trabalhar desses indivíduos estão cerceadas de uma multiplicidade de fatores.

Além disso, é importante dizer que esse modo de viver e trabalhar dos feirantes idosos permite considerar uma diversidade de realidades a que estão inseridos e se inserindo. Na verdade, os mecanismos construídos pela sociedade moderna de inserção precária desses sujeitos são modificados a partir da forma como eles conseguem manter interrelações sociais, pois apesar de a feira ser um espaço excluído das grandes formas de mercado, esta, por sua vez, possibilita incluir indivíduos excluídos dos grandes mercados.

Devemos salientar, por outro lado, que apesar de se manterem nessa forma de trabalho, isso não significa a saída deles de condições de pobreza em que, muitas vezes, se encontraram. No entanto, e apesar das dificuldades e do desconforto sob o qual realizam essa atividade de feirante, eles conseguem (re)criar laços de proximidade na feira, tendo esta um papel socializador importante para estas pessoas, que a vêem como oportunidade de serem úteis, de continuarem interagindo e de manter as amizades construídas fora dos grupos domésticos, sítios/povoados e de alguns espaços dos pequenos municípios.

Portanto, anunciar a "morte dos idosos" da sociedade moderna é desconsiderar que eles estão vivos e que, a depender dos espaços sociais, eles conseguem mostrar suas capacidades. E mais do que isso, (re)estruturam os valores confiança, reputação, honra e responsabilidade entre os indivíduos, possibilitando assim o reconhecimento deles como agentes da sociedade.

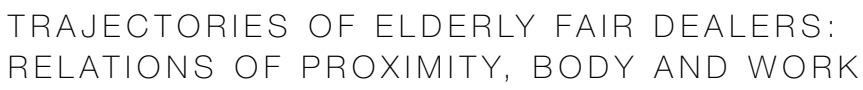

This article aims to discuss the many conceptions of work, body and aging through the relations of proximity consolidated in the trajectory of elderly fair dealers from Delmiro Gouveia fair in Alagoas. The research was conducted in a qualitative and quantitative way. The data 
were obtained through field research with aid by techniques question and semi-structured interviews. The research demonstrated the need to loosen the view sometimes physical, sometimes merely social to show that the life trajectories of these subjects are surrounded by relations of proximity, from the productive-economic orders to the social and political ones, which allow their social reproduction.

keywords

Aging. Body. Work. Relations of Proximity.

\section{referências}

BEAUVOIR, Simone de. A velhice. 5. ed. Rio de Janeiro: Nova Fronteira, 1990

BOSI, Eclea. Memória e sociedade: lembranças de velhos. 16. ed. São Paulo: Cia. das Letras, 2010.

BRANDÃO, Carlos Rodrigues. A partilha da vida. São Paulo: GEIC/Cabral, 1995.

BRAUNSTEIN, Florence; PÉPIN, Jean-François. O lugar do corpo na cultura ocidental. Lisboa: Piaget Editora, 1999.

CANDIOTTO, Luciano Zanetti Pessôa; CORRÊA, Walquíria Kruger. Ruralidades, urbanidades e a tecnicização do rural no contexto do debate cidade-campo. Campoterritório: revista de geografia agrária, Uberlândia, v. 3, n. 5, p. 214-242, fev. 2008.

CARNEIRO, Maria José. Ruralidade: novas identidades em construção. Estudos sociedade e agricultura, Rio de Janeiro, v. 1, n. 11, p. 63-75, out. 1998.

ELIAS, Norbert. Introdução à Sociologia. Braga: Edições 70, 1980.

FREITAS, Maria Célia de et al. O significado da velhice e da experiência de envelhecer para os idosos. Revista da Escola de Enfermagem da USP, v. 44, n. 2, p. 407-412, jun. 2010.

GARCIA-PARPET, Marie. Feira e trabalhadores rurais: as feiras do Brejo e do Agreste Paraibano. 1984. 237 p. Tese (Doutorado em Antropologia Social) - Museu Nacional, Universidade Federal do Rio de Janeiro, Rio de Janeiro, 1984.

JORDÃO NEITO, Antonio. Gerontologia Básica. São Paulo: Lemos, 1997.

MALDAUN, Daise et al. Espiritualidade / Religiosidade. In: NERI, Anita Liberalesso (Org.). Palavras-Chave em Gerontologia. Campinas: Alínea, 2008. p. 70-74.

MASCARO, Sonia de Amorim. O que é velhice. São Paulo: Brasiliense, 1997.

MAUSS, Marcel. Sociologia e Antropologia. v. 1 e 2. São Paulo: EPU/EDUSP, 1974.

MELO, Samuel Pires. Trajetórias de proximidade, redes e feiras: as práticas de agricultores familiares feirantes em Água Branca e Delmiro Gouveia, Alagoas. 2012. 255 p. Tese (Doutorado em Sociologia) - Universidade Federal de Pernambuco, Recife, 2012.

MENDRAS, Henri. Sociedades Camponesas. Rio de Janeiro: Jorge Zahar Ed., 1978. 
MINAYO, Maria Cecília Souza; COIMBRA, Junior Carlos Everaldo Alvares. Antropologia, Saúde e Envelhecimento. Rio de Janeiro: Editora Fiocruz, 2002.

SABOURIN, Eric. Camponeses do Brasil: entre a troca mercantil e a reciprocidade. Rio de Janeiro: Garamond Universitária, 2009.

SANTOS, Maria de Fátima Souza. Identidade e aposentadoria. São Paulo: Pedagógica e Universitária LTDA., 1990.

SILVA, Janaína Carvalho da. Velhos ou idosos. A terceira idade, São Paulo, v. 14, n. 26 p. 94-111, jan. 2003.

WANDERLEY, Maria de Nazareth Baudel. Urbanização e ruralidade: relações entre a pequena cidade e o mundo rural. Recife: UFPE, 2001. Disponível em: <http://fundaj. gov.br/observanordeste/obed001f.doc>. Acesso em: 12 set. 2008.

Recebido: 03/09/2013

Aceite Final: 08/11/2013 